\title{
Novos elementos teórico-metodológicos para os estudos migratórios em fronteira
}

"É o mistério profundo, é o queira ou não queira". (Tom Jobim)

\author{
Marco Aurélio Machado de Oliveira*
}

JARDIM, Denise F. Imigrantes ou refugiados? Tecnologias de controle e as fronteiras. Jundiaí, SP: Paco Editorial, 2017.

Um dos elementos mais banalizados em projetos de pesquisa, quando se referem aos procedimentos metodológicos, é a revisão bibliográfica. Mais do que uma seleção do que deverá ser utilizado no decorrer de uma investigação, esse procedimento é aquilo que Said (1998) denominou como "preparo estratégico", que municiará o investigador perante o pensamento que as autoridades sobre dado assunto fazem uso. Entendemos se tratar de uma prática que deva requerer existência permanente. E, nesse sentido, a obra em tela muito colabora, pois insere, com profundidade e abrangência, temáticas relacionadas às migrações internacionais muitas vezes subestimadas pelos investigadores, especialmente quando abordadas em fronteira. Ganha em relevância, também, por ser uma obra que servirá aos estudos de antropólogos, geógrafos, historiadores, sociólogos, demógrafos e demais áreas do saber. Ou seja, a interdisciplinaridade é uma silhueta metodológica muito viva neste livro. Uma discussão no âmbito acadêmico com os componentes que aparecem no título da obra nos obriga a levar em conta que as categorias que permeiam sua análise podem ser entendidas como constitutivas da economia da migração.

\footnotetext{
* Universidade Federal de Mato Grosso do Sul (UFMS), Corumbá-MS, Brasil (marco.cpan@gmail.com; https://orcid. org/0000-0003-3749-6030).
} 
Com olhar de perita, a autora contribui muito ao distinguir uma antiga retórica, presente nas esferas estatais e mundanas: a porosidade das fronteiras como sinônimo de "ausência" do Estado. Ou seja, ela clareia a fronteira como palco de reivindicações bastante diversificadas, sejam as que clamam por isonomias com relação ao restante da nação, sejam as que evocam suas diferenciações referentes ao combate à sua porosidade. $\mathrm{E}$, quanto mais se aproxima da "porosidade" fronteiriça, mais se evidencia a resistência das vidas que ali habitam e das que ali encontram um espaço de deliberações. Seja no poder expresso pelo domínio cartográfico ou pelos números demográficos, a fronteira e a migração, aqui indissociáveis, continuam sendo tratadas como "problemas" nas esferas estatais, enquanto nos fluxos de vida permanecem como "soluções". A autora inclui a fronteira como elemento de estabilizações, reivindicações e tensões tanto no aspecto administrativo como na trajetória do migrante internacional. Nesse sentido, quando se juntam as categorias migrantes internacionais e fronteira, vemos aplicado um dos ensinamentos mais importantes de Sayad (1998), que é a necessidade de qualificar o espaço percorrido pelo imigrante, dando-lhe a devida e honesta interdisciplinaridade.

A marcação da fronteira encontra nesta obra importantes colaborações para os estudos migratórios: seja quando a autora insere discussão a respeito da força da lei ou de seus agentes e da "força retórica dos mapas" (JARDIM, 2017, p. 97), seja pela lógica perversa que seleciona o "bom imigrante" (JARDIM, 2017, p. 206), a marcação central é a vigilância como meio de controle. Dessa forma, o livro trata, também, das autoridades e dos meios que elas possuem para efetivarem suas obrigações legais e contratuais. A utilização do conceito foucaultiano de governamentalidade tem coerência com os ensinamentos de Denise Jardim nesta obra, pois não se busca mais controlar as pessoas, mas sim as coisas que as pessoas se tornaram do ponto de vista jurídico e estatal. Nesse aspecto residiu uma escolha feita pela autora quanto à forma de abordar a temática fronteiriça. Embora, a princípio, o livro possa conduzir ao entendimento no qual a mesma não teria assumido uma epistemologia de fronteira, no desenvolvimento da leitura percebe-se o contrário, ou seja, o conceito de governamentalidade que ela adota está coerentemente ligado aos seus estudos sobre os meios de controle em fronteira.

Outro relevante aprendizado metodológico trazido pela obra refere-se à geração de dados relativos aos imigrantes e refugiados. Sobre esse tema há diversas publicações e alguns autores chegam a classificá-los como "incontáveis". Denise Jardim nos conduz de forma muito elucidativa a um entendimento no qual a invisibilidade dos migrantes internacionais é, por um lado, uma estratégia desses sujeitos e, por outro, um protocolo administrativo. Esse escudo implantado pela invisibilidade não é exclusivo dos que fazem uso da fronteira para ingresso em um território nacional e que lá não permanecem. Também é recurso daqueles que vivem na fronteira, seja permanecendo em um dos países, seja morando em um e trabalhando ou estudando no outro, os chamados imigrantes pendulares.

Um importante ganho ao ler este livro é a permanente revisão conceitual que se propõe da primeira à última página. Isso é demonstrado, inclusive, na sua estrutura dividida em 
duas partes: a primeira, Tecnologias, e a segunda, Fluxos de Vida, contendo três capítulos em cada uma delas. Tal estruturação em momento algum conduz o leitor a um divórcio temático, senão ao contrário, pois inclina suas observações no sentido da evidente justaposição que o livro confirma. E uma das coerências da divisão em duas partes do livro está em mantê-las coesas.

Na primeira parte, o capítulo 1, denominado "As materialidades das tecnologias", o capítulo 2, intitulado "As tecnologias de precisão e suas dinâmicas", e o terceiro capítulo, chamado "As zonas de urgência e os agentes da governamentalidade", são muito bem construídos, dando coesão e coerência às ideias centrais abordadas pela autora. 0 fio que conduz sua análise é a tecnologia, nos levando a entender as formas como essas ferramentas de controle são incorporadas em um ambiente para o qual o migrante internacional é direcionado. Tais tecnologias e direcionamentos conduzem a uma zona cinzenta elucidada nesses capítulos, qual seja: por um lado, são impostas codificações e lógicas funcionais aos migrantes internacionais; e, por outro, estas são banalizadas no cotidiano de tal forma que são percebidas como instrumentos de circulação, ficando evidente que elas estão a serviço de um controle sobre as pessoas. A autora avalia as complexas vinculações que existem entre as instâncias jurídicas e administrativas, observando como isso é transmitido ao migrante internacional no sentido de transparecer confiabilidade no processo a que está submetido. Isso de tal forma que os aspectos jurídicos, ao serem incorporados aos administrativos, garantiriam a esses sujeitos centrais de seus estudos confiança nos difíceis caminhos a serem percorridos na decodificação do que lhes é imposto.

Jardim trata de uma intrincada relação entre as altas e baixas políticas sobre a temática migratória. A autora esclarece que as deliberações nas esferas superiores, seja nos âmbitos jurídicos ou administrativos, impõem às esferas inferiores, por um lado, dificuldades operacionais que se expressam nas formas de "visibilidade" ou "invisibilidade" ou de "autoridade" e, por outro, as maneiras com as quais os agentes que atuam na fronteira incorporam os sentidos de governamentalidade nas deliberações.

Na segunda parte, os capítulos 4, “Quem quer ser refugiado?”, 5, “Zonas de abandono: as invisibilidades cotidianas”, e 6, “Os paradoxos da regularização”, trazem os migrantes internacionais sob o olhar minucioso de uma humanista clássica. São apresentados os fluxos de vida sob a perspectiva de um posicionamento que a pesquisadora assumiu no correr de seus estudos sobre o processo migratório internacional. Ou seja, ela reconhece a fronteira como espaço altamente privilegiado para o entendimento do curso migratório, porque ali estão à espera desses grupos oportunidades e permissões, ou a ausência de ambas. Segundo Foucher (1991), o imigrante sabe bem o que o espera na fronteira, e isso é evidenciado no correr da leitura dessa segunda parte, especialmente, à medida que avança na combinação dentre histórias de vida e governamentalidade. Ao analisar os palestinos e as haitianas grávidas no sul do Brasil, estrategicamente, a autora nos reserva as equatorianas na Espanha como um relevante contraponto aos processos e às respectivas dimensões geográficas que ela se propõe. Nesse aspecto, a segunda parte do livro traz a combinação 
de trabalhos de campo na América do Sul, com migrantes do Caribe e do Oriente Médio, e na Europa, com sul-americanas. Aparece de forma clara como a fronteira é, também, uma instância que se alarga além dos limites internacionais e os migrantes internacionais se prontificam a fazer uso da pedagogia da governamentalidade em diversos espaços.

Dois outros importantes procedimentos metodológicos contidos nesta obra estão no campo político e na formação intelectual da autora. No primeiro, a leitura é conduzida no sentido de melhor compreender a dinâmica existente entre as altas e baixas políticas, bem como as formas como os órgãos e organizações ligados aos direitos humanos adquirem plasticidades diante das ordens políticas, jurídicas e administrativas. No segundo, por meio de seus trabalhos etnográficos, é possível redimensionar a palavra "interlocução", principalmente, a partir do "acúmulo de indagações" que foram os fiéis depositários de suas pesquisas.

Retornando ao traço humanista da autora, os personagens adquirem posicionamentos que revelam não apenas suas deliberações pregressas - tanto do migrante em sair de sua terra natal, quanto dos agentes públicos, notadamente oriundos de outras regiões, que não a fronteira -, mas também as formas como se deparam um ao outro nas instâncias de deliberações. Isso porque a fronteira é instância onde se efetivam, ao menos, dois fenômenos que atingem a administração estatal: a globalização (festejada por alguns) e a migração internacional (alvo de intensas preocupações pelos mesmos). Assim, essa obra contribui para a construção de um entendimento sobre as complexas maneiras de agir e pensar nas quais os agentes do Estado se assentam em alguns momentos, em especial naqueles de tomada de decisão. Ao estudar esta obra entendemos melhor que a ordem das nações, que Abdelmalek Sayad (1998) já havia desvendado, aflora nas fronteiras sem cinismos e impõe preocupações, uma vez que a migração internacional está sob o olhar atento e severo do estado.

\section{Referências}

FOUCHER, M. Fronts et Frontières. Paris: Fayard, 1991.

SAID, E. Orientalismo. Trad. de Tomás Rosa Bueno. São Paulo: Cia das Letras, 1998.

SAYAD, A. A imigração: ou os paradoxos da alteridade. Trad. de Cristina Murachco. São Paulo: Edusp, 1998.

\section{Sobre o autor}

Marco Aurélio Machado de Oliveira é doutor em História Social pela Universidade de São Paulo (USP). Professor titular na Universidade Federal de Mato Grosso do Sul (UFMS), docente permanente do Mestrado em Estudos Fronteiriços da UFMS e membro do GT América Latina y Medio Oriente na Clacso. 


\section{Endereço para correspondência}

Rua Domingos Sahib, s/s, Porto Geral

79304-290 - Corumbá-MS, Brasil

Recebido para publicação em 01/11/2018

Aceito para publicação em 10/12/2018 